\title{
How to measure innovation in radiotherapy: an application of the Delphi method
}

\author{
Maria Jacobs ${ }^{* 1}$, Liesbeth Boersma ${ }^{2}$, Andre Dekker ${ }^{2}$, Mark Govers ${ }^{3}$, Philippe Lambin ${ }^{2}$, Frits van Merode ${ }^{4}$ \\ ${ }^{1}$ Department of Radiation Oncology (MAASTRO), School for Public Health and Primary Care-Health Services Research, \\ Maastricht University Medical Centre, Maastricht, the Netherlands \\ ${ }^{2}$ Department of Radiation Oncology (MAASTRO), GROW School for oncology and Developmental Biology, Maastricht \\ University Medical Centre, Maastricht, the Netherlands \\ ${ }^{3}$ Department of Health Services Research, School for Public Health and Primary Care (CAPHRI), Maastricht University, \\ Maastricht, the Netherlands \\ ${ }^{4}$ Executive board of Maastricht University Medical Centre, Maastricht, the Netherlands
}

Received: February 26, 2015

DOI: $10.5430 /$ jha.v4n4p14
Accepted: April 24, $2015 \quad$ Online Published: May 4, 2015

URL: http://dx.doi.org/10.5430/jha.v4n4p14

\begin{abstract}
Objective: Innovation is an important driver for improving the quality of health care, yet a tension exists between innovation and providing cost-effective health care. To develop strategies that promote innovation, parameters are needed that are indicative of innovation. However, no recognised indicators of innovation in radiotherapy are currently available. The aim of this study is to fill that gap by providing a framework for measuring innovation. This should facilitate future multi-centric studies on strategies aimed at promoting innovation in radiotherapy.

Methods: We applied the Delphi method in four rounds. The chairpersons of all Dutch radiotherapy departments were asked to suggest indicators. The resulting inventory was assessed by a number of Dutch radiation oncologists, medical physicists and managers. After implementig a cut-off score on suitability and measurability, we asked Dutch professors on innovation to assess the remaining indicators. Finally, the chairpersons reached consensus.

Results: On the basis of the Delphi study, we derived 13 indicators in four categories, more specific product innovation, technology innovation, market innovation and organisational innovation, for measuring both incremental and radical innovations in radiotherapy; these indicators are also suitable for measuring the generation and adoption of innovations.

Conclusions: We were successful in reaching consensus amongst the experts on indicators that measure innovations in radiotherapy. The developed tool will be used to investigate the relation between innovation and possible factors inhibiting or stimulating successful innovation and between the level of innovation and its effects.
\end{abstract}

Key Words: Innovation, Radiotherapy, Delphi method, Innovation indicators, Innovation measures

\section{INTRODUCTION}

As in general healthcare, there is an increasing pressure in radiotherapy to deliver cost-effective treatment. ${ }^{[1]}$ This pressure threatens the continuous development and implementa- tion of innovations, and thereby the quality of radiotherapy, since innovation has been shown to be an important driver of quality care. ${ }^{[2-9]}$ Technological innovations in radiotherapy have, for instance, resulted in better treatment outcomes by

\footnotetext{
*Correspondence: Maria Jacobs; Email: maria.jacobs@maastro.nl; Address: Department of Radiation Oncology (MAASTRO), School for Public Health and Primary Care-Health Services Research, Maastricht University Medical Centre, Maastricht, the Netherlands.
} 
fostering the ability of radiation oncologists to deliver radiation more precisely, increasing the dose to tumour targets and reducing the dose to normal tissues and critical structures. ${ }^{[10,11]}$ This is in line with findings in general hospitals; Wu et al., for example, have shown that medical and administrative innovations have a positive effect on care outcomes. ${ }^{[9]}$ The tension between cost containment and innovation can be felt at several levels.

First of all, the tension between innovation and cost containment arises in particular in situations where innovations and daily practice are integrated, as is the case in many radiotherapy departments, which are often affiliated to or embedded in a university medical centre. ${ }^{[12-14]}$ Whereas efficiency requires standardisation and meta-routines for non-routine activities, small-step or incremental innovations call for experimentation (on existing practices) and experience-based approaches. ${ }^{[15,16]}$ To develop and implement innovations, treatment processes are in constant evaluation and experiments must be conducted to improve processes and treatments. Such an approach demands additional means and experimentation time, which could be regarded as a waste if the experiment turns out to be unsuccessful.

Second, the organisational conditions and organisations' management styles vary from efficiency-oriented to more experiment-oriented organisations. In an efficiency-oriented setting, monitoring, controlling and a coordinative management style are required. ${ }^{[17]}$ In an experimental setting, a consultative, coaching management style is more suitable. ${ }^{[18]}$ If an organisation strives to make not just incremental but also more radical and major innovations, the demands for organisational conditions and management style will change again, as new external knowledge has to be imported. An adhocratic, entrepreneurial and visionary management style is paramount when radical innovations are to be made, because this can encourage employees to move across organisational and technical boundaries. ${ }^{[15,17,19]}$

A third aspect that influences the degree of tension, is the distinction between generating innovation by means of research and adopting innovations. Some experts suggested that innovation refers solely to the implementation of new or significantly improved treatment or technologies. Others state that innovation can also refer to research that generates new knowledge. This distinction is important because generating innovation requires different conditions than implementing innovations or improving efficiency. ${ }^{[14]}$ Aiming for all these aspects simultaneously might cause tension in the organisation, because of conflicting requirements.

Since continuous innovation is essential for improving the quality of care, ${ }^{[2-9]}$ the tension between cost containment and innovation as described above needs to be handled adequately. Organisations that are more successful in this respect may for example adapt their management style to the situation at hand. ${ }^{[20]}$ To investigate which strategies are effective in stimulating different kinds of innovations, measurable and validated indicators are needed to measure innovation. These indicators could help organisations to develop and monitor their innovation ability and practices, by clarifying what they need to focus on in order to maximise their innovation success rate. ${ }^{[21]}$ Because our research concerns the field of radiotherapy, we need to find indicators that are suitable for measuring innovation in radiotherapy centres.

In literature no closely defined or generally accepted approach has been found for measuring innovation in general. ${ }^{[8,21-23]}$ For the service sector, to which health care including radiotherapy more or less belong, indicators have been developed and listed in the Community Innovation Survey (CIS). ${ }^{[24]}$ The development of the CIS was instigated by the European Commission, as a follow-up of the OECD initiative (Organisation for Economic Co-operation and Development) to develop a manual for a survey on innovation. The guidelines of the OECD manual only comprised manufacturing activities and technological and product innovation. ${ }^{[25]}$ However, the CIS also has limitations in the sense that it is focussed on technological innovation and concentrates mainly on business services and not on health care. ${ }^{[26,27]}$ Previous research has emphasised that a sector-specific measurement tool is needed "in this case radiotherapy-specific" because activities can vary greatly within the different service sectors. ${ }^{[28]}$ Furthermore, measurement tools have to render a very exact measurement of what is most important in a certain innovation phase in a particular sector, and register specific characteristics such as knowledge-intensity. ${ }^{[21,29]} \mathrm{Fi}$ nally, embedded knowledge must be measured as well; this is knowledge that is not codified but is "stored" in individuals' minds or organisational routines. ${ }^{[21]}$

Several studies on innovation indicators have been conducted which show that, over time, innovation indicators have evolved, becoming progressively more complex and meaningful. ${ }^{[21,30,31]}$ In fact, there are potentially hundreds of indicators imaginable. Which indicators are most suitable for measuring innovation in a specific situation or sector is still debatable, however, and needs to be clarified in each specific sector and situation such as in our case in radiotherapy. ${ }^{[32,33]}$

The aim of this study is to identify indicators of innovation that are suitable for measuring innovation in radiotherapy. It is required that these indicators can be applied in a multicentric setting, can capture both incremental innovation and more radical innovations, and can distinguish between generating and implementing innovations. 


\section{METHODS}

We applied the Delphi method to identify the indicators with four rounds (see Figure 1). ${ }^{[34,35]}$ This method makes it possible to consult both experts in the field of radiotherapy and experts in the field of innovation (professors with a chair related to the field of innovation). This method has been successfully followed in radiotherapy research as well as other research fields. ${ }^{[36-42]}$

Since no patients were involved in our surveys, the law in the Netherlands does not require ethics clearance.

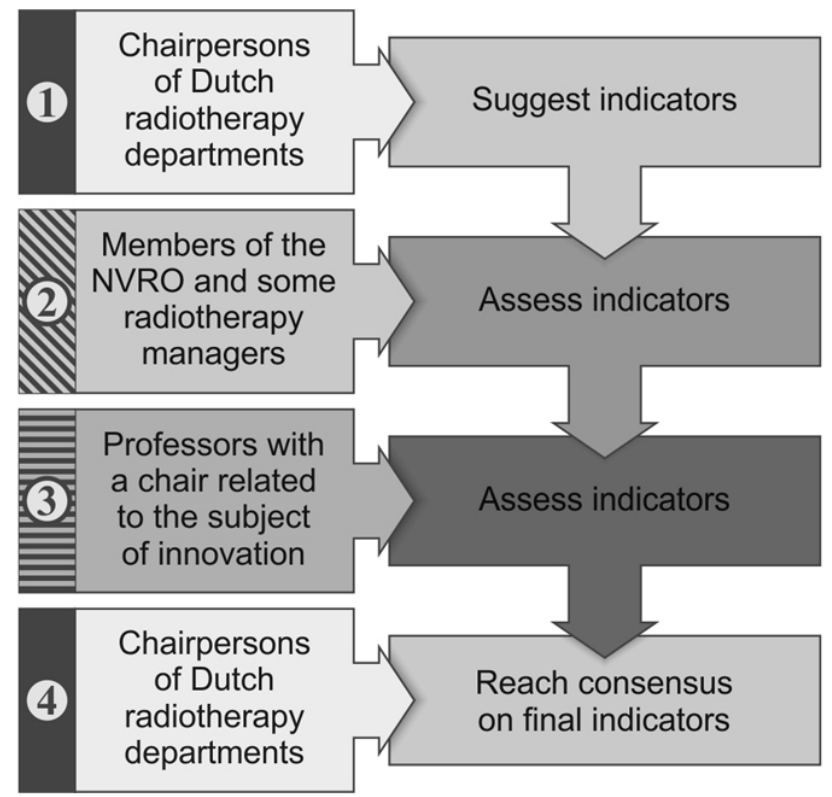

Figure 1. Overview of the Delphi rounds

\subsection{Round 1}

\subsubsection{Methods and materials}

Based on literature, we distinguished four types of innovation. ${ }^{[43]}$ For each type of innovation, we started by defining a few indicators in a brainstorm session in our clinic $(\mathrm{MJ} / \mathrm{LB} / \mathrm{AD} / \mathrm{PL})$. These indicators were put together in a questionnaire, sent out in Round 1 to the chairpersons of all 21 Dutch radiotherapy departments (experts in radiotherapy). The chairpersons were asked to agree or disagree with the indicators listed and to suggest additional indicators.

\subsubsection{Data analysis}

All suggested indicators were included in the next round without further assessment.

\subsection{Round 2}

\subsubsection{Methods and materials}

The indicators (96) suggested by participants in Round 1 were put in a questionnaire. The questionnaire was sent to a group of 330 people, mainly members of the NVRO (the
Dutch Society for Radiation Oncology) and a small number of managers active in the radiotherapy domain (also experts in radiotherapy). These people were asked to rate each indicator on its suitability and measurability. A 5-point Likert scale was used for all answers; participants could also add comments of their own. To improve the response rate, two questionnaire reminders were sent out.

\subsubsection{Data analysis}

We ranked the indicators obtained in the second round on the basis of agreement of the scores assigned by the respondents. To do this, we calculated the mean scores and interquartile ranges (IQR). ${ }^{[44]}$ The IQR is the absolute value of the difference between the $75^{t h}$ and $25^{t h}$ percentiles, with smaller values indicating a higher degree of consensus.

Indicators were selected on the basis of a cut-off: a mean score of $\geq 3.00$ for suitability, $\geq 3.50$ for measurability and an IQR of 2. This cut-off value was chosen in a way that the number of indicators was reduced to the most suitable and measurable ones; literature shows that it is important to keep the list of indicators as short and simple as possible. ${ }^{[45]}$ Because suitability was also assessed by the innovation professors (which also reduced the number of indicators to the cut-off), we decided to set the cut-off for measurability at 0.5 higher than for suitability. We used a box-plot analysis to determine whether the experts differed in their opinions on the suitability and measurability of the indicators.

\subsection{Round 3}

\subsubsection{Methods and materials}

We sent a questionnaire to 26 innovation experts (all Dutch professors with a chair related to the field of innovation, as described on their universities' websites), asking them to approve or reject the indicators suggested by the radiotherapy experts, so as to obtain greater certainty that the indicators did indeed measure innovation.

\subsubsection{Data analysis}

We decided to accept an indicator if it was not rejected by the majority of the Round 3 innovation experts assessing the indicator. To promote consistency in terminology, we reformulated some of the indicators.

\subsection{Round 4}

\subsubsection{Methods and materials}

We sent a questionnaire to the Round 1 chairpersons of radiotherapy departments if they agreed with the indicators chosen in the previous rounds.

\subsubsection{Data analysis}

Research into Delphi studies shows that no clear criteria are available for the moment when consensus is reached. ${ }^{[46]} \mathrm{We}$ 
decided that consensus had been reached when $80 \%$ of the Round 1 respondents agreed that the selected indicators were good measures for the four types of innovation, because this is the percentage that is usually applied. ${ }^{[36]}$ After consensus was reached, the Delphi study was closed.

\section{Results}

\subsection{Response rate}

In Delphi Round 1, 15 of the 21 chairpersons from the radiotherapy departments we approached accepted the invitation to participate in our study; one person asked if they could skip Round 1. In the end, 14 chairpersons responded to the questionnaire on indicators.

The Round 2 questionnaire had a $20 \%$ response rate, and was completed by 66 of the 330 invited NVRO members/managers of radiotherapy departments. An additional 56 of the 330 invitees (17\%) stated their reason for not participating in the study.

In Round 3, 18 of the 26 professors with a chair related to innovation who we approached gave an initial reply. Four of these professors added comments but made no assessment, while another four people stated that, due to circumstances, they had no time to participate. In total, 10 of the 26 professors we approached assessed the indicators.

In Round 4, 14 of the 15 chairpersons of Dutch departments of radiotherapy reached an agreement on the indicators sug- gested in the previous rounds.

\subsection{Indicators for innovation}

Round 1 resulted in a lot of possible indicators (96 indicators).

The analysis of the Round 2 assessments resulted in 17 remaining indicators. After comparing these indicators with the literature, we moved one indicator from "product innovation" to "technological innovation". [47] The box-plot analysis showed that there were no significant differences between the appraisal by different professionals $(p>.05)$.

In Round 3, the professors we consulted varied in their opinion on the indicators suggested. In some cases, the professors suggested we reword an indicator. We reformulated some of the indicators to make them more consistent. We used the wording chosen in the CIS for a number of comparable indicators. Because only one indicator remained for organisational innovation, we also added some relevant indicators from the CIS to our list.

In Round 4, 14 of the 15 chairpersons responded to the list resulting from Round 3. The experts all approved of the indicators suggested, which renders a $93 \%$ consensus, far more than the required $80 \%$ usually applied in Delphi studies. ${ }^{[36]}$ Figure 2 presents an overview of the radiationoncology-related indicators of innovation that were finally agreed upon.

\begin{tabular}{l} 
Product innovation \\
\multicolumn{1}{c|}{ during the past three years } \\
1. Number of introductions of \\
new or significantly \\
improved treatments \\
- New to radiotherapy \\
- New to your clinic \\
2. Number of new positioning \\
devices for patient treatment \\
(e.g. a new fixation product) \\
3. Number of approved patents \\
(available from a public \\
database) \\
4. Percentage of patients in \\
phase III randomised trials \\
approved by an IRB \\
(Institutional Review Board) \\
5. Percentage of patients in \\
phase I-II trials approved \\
by an IRB (Institutional \\
Review Board)
\end{tabular}

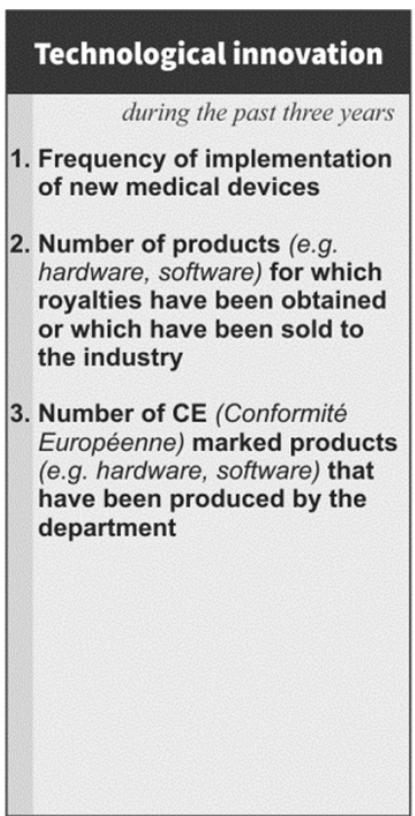

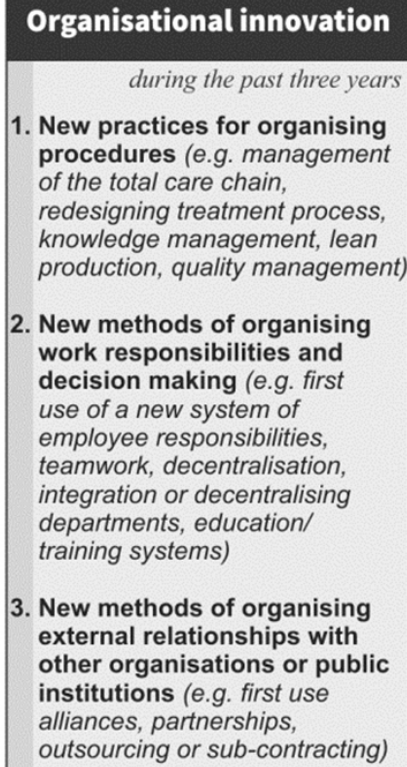

2. New methods of organising work responsibilities and decision making (e.g. first use of a new system of employee responsibilities, teamwork, decentralisation, integration or decentralising departments, education/ training systems,

3. New methods of organising external relationships with other organisations or public institutions (e.g. first use alliances, partnerships, outsourcing or sub-contracting)

Figure 2. Overview of radiation-oncology-related innovation indicators on which consensus was reached in the final round 


\section{Discussion}

This paper describes the first attempt to develop a set of indicators that measure innovation in radiotherapy. Our Delphi study design seems to have been an effective tool for generating such indicators. Unlike the approach taken in most Delphi studies, we included experts from different disciplines, namely, the fields of radiotherapy and innovation. ${ }^{[37]}$ The advantage of taking this approach was that we could combine the knowledge and insights from experts in radiotherapy with those from experts in the field of innovation. We considered it important to apply such an integrated approach, because as yet no clear picture of innovation exists in the literature, or in the fields of innovation and radiotherapy.

The indicators of innovation we developed could be applied in future studies aimed at analysing and quantifying the aspects of innovation that are either present or absent in radiotherapy departments. The indicators could subsequently be used to find the keys to improving innovation. The latter in particular would be extremely useful, as innovation is often thought to be related to the quality of care.

\subsection{Views on innovation in radiotherapy derived from the literature}

Innovation is a complex concept. ${ }^{[48]}$ The literature on innovation is extensive, offering many different, but often vague definitions. ${ }^{[15]}$ Indeed, only a few well-designed studies on health care can be said to exist. ${ }^{[49]}$ A frequent problem is that often it is not clear from which viewpoint innovation is being approached. For example, the focus of study can be on the process of innovation, the degree of novelty of the endproduct, product content or organisational competence. ${ }^{[15]}$

In our study, we decided to select the three viewpoints we assumed to be most relevant for the development of measurement indicators. The first viewpoint concerns the type of innovation. Describing innovation on the basis of the type of innovation was done as early as 1934, and has had widespread applications since then. ${ }^{[43]}$ In this view, a distinction is made between innovation as concerning new products (e.g. in radiotherapy new treatments such as stereotactic body radiation therapy have been introduced), new technology or production methods (e.g. new planning methods, such as atlas based planning), new markets (e.g. a new hospital referring patients), new forms of organisation (e.g. a lean redesign), or new sources of supply of raw materials or halfmanufactured goods (in radiotherapy, an example could be that of using a mouldable rubber bolus instead of the outmoded wax bolus). The last type of innovation, introducing new sources of supply, does not occur frequently in radiotherapy, which is why we excluded this type from our study. All other types are included.
The second viewpoint concentrates on the innovation competence of the organisation and makes a distinction between generating innovation by means of research and the adoption of innovations by organisations or units. ${ }^{[14]}$ Distinguishing between the generating and adopting innovations is essential, because the organisational conditions required for each activity can vary considerably. ${ }^{[15]}$ As a consequence, organisations that both try to generate and adopt innovations could experience tension in daily practice. Further research needs to point out whether this is actually the case.

The third and final viewpoint centres on the degree of innovation, with a special focus on radical innovation (innovations which discontinue the existing practice of treatments, technology, markets or organisational behaviour, systems, structures and so on) in knowledge-intensive firms. ${ }^{[15]}$ We believe that radiotherapy centres can be characterised as such. The MRlinac (completely new radiation equipment) is an example of such a radical innovation in radiotherapy.

As a last point to mention, the innovation process itself is not considered in this study, as our main interest lies in measuring the outcome of innovation.

\subsection{First viewpoint: types of innovation}

To categorise the indicators, we applied the first viewpoint. The professionals participating in the study were asked to submit indicators for each type of innovation. Below, we describe the types of innovation distinguished by converting them from Schumpeter and the third edition of the OECD manual to radiotherapy. ${ }^{[43,50]}$ We also compare our indicators with previous findings from the literature.

- Product innovation can be described as the introduction of treatments that are new or which constitute a significant improvement in terms of their characteristics or intended use. Such innovations include improvements in technical specifications, components and materials, incorporated software, user-friendliness and other functional characteristics. Product innovations sometimes utilise new knowledge or technologies.

We found five indicators for this type of innovation. Similar indicators are found in the literature. ${ }^{[20,30,31]}$

Our list contains a patent indicator. In the literature, there is some discussion about the appropriateness of this indicator. A systematic relationship has been found between an organisation's innovation output and its actual patenting behaviour. ${ }^{[51]}$ The correlation between these two factors is far from perfect, however. This might be due to research and development collaboration interfering with the correlation: contract 
research may result in patents being assigned to the one who pays for the research rather than the hospital which first registered the patent. Sometimes, too, it is said that services (to which the hospital sector belongs) tend to apply more frequently for copyright than for patents. ${ }^{[26]}$ Despite these considerations, we decided to keep the indicator on the list; as the discussion above implies, having no patents as a clinic does not necessarily mean that no innovation takes place. On the contrary, if patents are assigned to a clinic, this could be characterised as a form of innovation (generating innovation).

- Technological innovation is the implementation of a new or significantly improved treatment process or delivery method that has no noticeable consequences for the end-product. Technological innovation includes significant changes in the techniques applied, the equipment used or the available software. In our study, we decided to classify a new method as a technological innovation only if it led to renewal of the production process or constituted a significant improvement, without immediate and noticeable consequences for the patient. We also proceeded from the view that the acquisition of entirely new equipment or devices should always be labelled as technological innovation, irrespective of the effects on the patient - except when a completely new treatment is introduced, for example, using protons.

Our indicators of technological innovation concur with the Schumpeterian definition, because they all refer to production methods. In the literature, input indicators such as Research \& Development expenditures are sometimes used to measure technological innovation. However, as stated, in recent years output indicators have been described as being more suitable. ${ }^{[32,52]}$ Studies on technological innovation often focus on manufacturing, and examples of the output indicators used in these studies all refer to production methods, such as new production techniques, automation, and fundamentally new production systems. ${ }^{[53]}$ In addition, output indicators of device innovation are often used, such as the number of products regulated by the FDA for medical devices (comparable to the European indicator of CE [Conformité Européene] marking). ${ }^{[54]}$

Lastly, there exists a body of literature on LiteratureBased Innovation Output (LBIO) indicators that are generated by sampling the "new product announcement" section in technical and trade journals, a method which is also applied in public services. ${ }^{[48,52]}$ Converting this procedure to radiotherapy is not impossible, but it would be very complex and labour-intensive.

- Market innovation refers to new patients, and includes the opening up of a new hospital market in which the relevant clinic has not operated before. When it comes to market innovation indicators, our findings bear a close similarity to the results from previous research, such as the reports on "new customers gained through innovation" and "number of new customers of new products/services who go on to buy existing products/services". [55]

- Organisational innovation is the implementation of new or significant changes in clinic organisational structure or management methods aimed at improving the use of knowledge, the quality of treatments and services, or the efficiency of workflow. Such changes can include new practices of organisation procedures, new methods of organising work responsibilities and decision making, and new methods of organising external relationships with other organisations or public institutions.

Research on defining and measuring organisational innovation is still lacking due to a lack of empirical data, clear definitions and suitable measurement constructs. ${ }^{[56-58]}$ Organisational innovation is often rather broadly defined, and indicators vary greatly. ${ }^{[57]}$ An additional complexity is caused by the different types of organisational innovation that can be discerned, the long lifecycle of organisational innovations, differences in the extent of use and implementation of such innovations, and also by the fact that certain labels (e.g. teamwork) are differently formulated across organisations. The professors in innovation rejected three of the four indicators of organisational innovation. Strikingly, the radiotherapy experts, who have no theoretical background in innovation concepts, were able to formulate appropriate product, technology and market indicators, although they failed to formulate acceptable organisational indicators. The possible reason for this is that most radiotherapists focus on innovation within the content of radiotherapy, rather than on the processes that facilitate organisational innovation.

\subsection{Second viewpoint: innovation competence}

The second viewpoint we considered relevant for radiotherapy concentrates on how organisations or units generate and adopt innovations, which can be helpful for answering the question whether research can be seen as innovation. ${ }^{[14]}$ Two 
of the professors in innovation stated explicitly that implementation is a "conditio sine qua non" to classify something as an innovation; however, other professors approved our two research indicators of trials and patents, which pertains to innovations that are not necessarily implemented in practice. The question arises whether new knowledge that results from research but is not yet implemented in clinical practice must be considered as innovative. To answer this question, we applied two insights from the literature. First of all, sometimes a distinction is made between invention and innovation, with invention being the first mention of an idea for a new product or process, whereas innovation applies to the first time that an idea is commercialised. ${ }^{[47]}$ Although invention and innovation are sometimes hard to distinguish from each other, often there is a considerable time lag between the two stages. ${ }^{[59]}$ Secondly, in the literature a distinction is made between generating and adopting an innovation. ${ }^{[14]}$ Generating innovations is a creative process, which is characterised by variation, search, experimentation and discovery, and which produces new knowledge and information. Innovation adoption, on the contrary, is a problem-solving process, which is planned more tightly, and can be characterised by selection, refinement, choice and execution. In our opinion, actual implementation in the inventing organisation is not a "conditio sine qua non" for innovation in radiotherapy centres. The development of a new product, service, market or technology is valuable in itself, even if the innovation is not implemented in the organisation which first generated it. Indeed, the generation of innovative ideas creates the possibility to adopt the innovation elsewhere, and thus improve health care delivery in general. For this reason, we decided that the research indicators that survived the cut-off could all justifiably be included.

When considering our list of indicators, some clear innovation-generating indicators can be seen, for example, the patent indicator (indicator 3 ) and the research indicators on patients in clinical trials (indicators 4 and 5). All other indicators will have to be evaluated during actual measurement, with the researcher classifying a particular innovation as being of either the generating or the adoptive kind. By following such a procedure, it will be possible to measure the level of different innovation activities that can potentially cause tension in the organisation and which may constitute a hurdle for applying an innovation.

\subsection{Third viewpoint: degree of innovation}

The third and final viewpoint concentrates on the degree of innovation, with a special focus on more radical types of innovation (as opposed to incremental innovation). Radical innovations are mostly, but not always, based on yet unused engineering and scientific principles, and often open up new markets and potential applications. These innovations are non-linear, resulting in a discontinuation of the existing line regarding treatments, technology, markets, organisational behaviour, systems, structure and so on. ${ }^{[15]}$ Incremental innovation refers to alterations to existing products, which lead to improvement in content or efficiency. The latter type of innovation is mostly linear and continuous in character.

The view on degree of innovation can help to clarify discussions about the true nature of innovation. Some people (including some respondents in our Delphi study) qualify small innovations as an improvement rather than a true innovation. In our opinion, however, improvement can be regarded as incremental innovation, although the impact and underlying conditions are different than in the case of radical innovation. Our indicators do not aim to quantify how radical an innovation is, yet when measuring innovation in practice, all innovations can be classified by categorisation in terms of our indicators: they can range from incremental or radical, depending on the basis of the definition used and the subject of measurement. For example, incremental product innovation is innovation in existing products (e.g. hypo-fractionation in radiotherapy, as an advancement on conventional fractionation), while radical innovation signifies the development of a completely new product (e.g. proton therapy).

Capturing incremental innovation is difficult, however, because generally speaking incremental innovation is a continuous process that forms part of the daily routine of employees. ${ }^{[30]}$ It is therefore hard to measure all incremental innovation. Nonetheless, measurement can give an impression of the level of radical and incremental innovation which has been noted. This implies that, although we cannot get full information on the potential causes of tension, we can arrive at the best possible estimate. It is important to realise this, because the widely-held opinion is that the cumulative impact of incremental innovation might well be equivalent to - if not bigger than - the impact of radical innovation. To ignore this fact would result in a biased view. ${ }^{[47]}$

\subsection{Final remarks}

We expect that by using these indicators of innovation in daily practice, a distinction can be made between innovationgenerating and innovation-adopting activities, and between radical or incremental innovation. This can be done by comparing the innovation activities by type of innovation with the definitions concerning radical or incremental innovation and innovation generation or innovation adoption. It is important to make this distinction, because certain forms of innovation can create tension in an organisation, particularly if innovation takes place in an environment that is dominated to some 
extent by efficiency goals or considerations for patient care. Such tensions can hinder successful innovation.

In addition, it should be noted that, remarkably enough, all our remaining indicators concern output measures. This implies there is no need for factors to determine the efficiency of input indicators, such as the number of research staff, because high input does not necessarily mean high output of innovation. ${ }^{[32]}$

Finally, this study has focussed on innovation indicators without addressing the data collection methods to measure the level of innovation in radiotherapy centres. In the literature, a number of shortcomings are listed of data collection in organisations by means of questionnaires. ${ }^{[33,48]}$ Such data are not completely objective, as the respondent decides what exactly constitutes an innovation. Also, indicators from surveys sometimes suffer from estimated-answer bias and low response rates. This means that, to use our indicators in future studies, questionnaires are probably not the most suitable method. Instead, an approved protocol is needed, with one or two investigators systematically interviewing a specified sample of the staff in the centres involved.

\subsection{Limitations and further studies}

There are several limitations to our study. First, although the Round 1 response rate was reasonably good "with 14 out of 21 respondents (67\%) submitting indicators for innovation" the Round 2 response rate was much lower (20\%). A low response rate is also seen in many studies requiring response by physicians; Willis et al. showed for instance that only $1 / 3$ of the health care providers reported response rates higher than $60 \%$ in the $2005-2009$ period. ${ }^{[60]}$ Response rates as low as $5 \%$ to $10 \%$ are also commonly reported in health care. ${ }^{[61]}$ In our case, we think that the disappointing response rate in Round 2 can be explained by the fact that most of the potential respondents were radiotherapy professionals, who are not very active in the area of management. Since we used a third round, where we asked the professors with a chair in innovation to review the results gained so far, we feel that the response rate of Round 2 is unlikely to constitute a problem. Also, although this specific response rate was low, we still received feedback from a considerable group of professionals $(n=66)$. Furthermore, we only accepted indicators if consensus was reached in Round 4 between the department chairpersons: the review by the Round 2 NVRO members was just an aid for reaching consensus. For these reasons, we consider our results to be valid.

Second, in order to arrive at a workable set of indicators, we defined subjective cut-off scores for measurability and suitability. We feel comfortable with our decision, because our indicators are comparable to the indicators mentioned in the literature; nevertheless, our decision was not based on previous research, as the necessary data were not available.

Third, we performed this study in one country only (the Netherlands), which may affect the potential to generalise our results to different settings. Finally, to test the selected indicators, they need to be measured in practice. We recommend future research be done on testing the set, especially its measurability.

Having said all this, we do feel we have taken an essential first step towards developing indicators for measuring the degree and type of innovation in radiotherapy centres. It is clear that these indicators have to be validated further by measuring them in actual clinical practice. These validated indicators will then allow us to investigate the relation between innovation and its effects, and relate the degree of innovation in radiotherapy centres with organisational and work characteristics in further multi-centric studies.

\section{Conclusions}

We developed a tool for measuring the level of innovation in radiotherapy centres. This tool will be used to investigate in radiotherapy centres the relation between innovation and possible factors inhibiting or stimulating successful innovation and between the level of innovation and its effects. We expect that the resulting data will assist us in deciding how to organise our clinics to combine innovation with cost-efficient patient care.

\section{REFERENCES}

[1] Lievens Y, Van den Bogaert W, Rijnders A, et al. Palliative radiotherapy practice within Western European countries: impact of the radiotherapy financing system? Radiotherapy and oncology. 2000; 56(3): 289-95. http://dx.doi.org/10.1016/S0167-8140(00 ) 00214-0

[2] McKee M, Chow CK. Improving health outcomes: innovation, coverage, quality and adherence. Isr J Health Policy Res. 2012; 1(1): 43.
PMid: 23098127. http://dx.doi.org/10.1186/2045-4015-1 $-43$

[3] Apekey TA, McSorley G, Tilling M, et al. Room for improvement? Leadership, innovation culture and uptake of quality improvement methods in general practice. Journal of evaluation in clinical practice. 2011; 17(2): 311-8. PMid: 20438607. http: //dx.doi.org/10.1111/j.1365-2753.2010.01447.x

[4] Agha L. The Effects of Health Information Technology on the Costs 
and Quality of Medical Care. Journal of health economics. 2014. PMid: 24463141. http://dx.doi.org/10.1016/j.jhealeco. 2013.12.005

[5] Blayney DW. Enhancing quality through innovation: American Society of Clinical Oncology presidential address 2010. Journal of Clinical Oncology. 2010; 28(28): 4283-8. PMid: 20697071. http://dx.doi.org/10.1200/JC0.2010.31.1696

[6] Karanikolos M, Ellis L, Coleman MP, et al. Health systems performance and cancer outcomes. JNCI Monographs. 2013; 2013(46): 7-12. PMid: 23962507. http://dx.doi.org/10.1093/jncimon ographs/lgt003

[7] O'Higgins N. Advancing cancer care: the quality spiral. Irish journal of medical science. 2014; 183(1): 7-13. PMid: 24166048. http://dx.doi.org/10.1007/s11845-013-1029-4

[8] Walker K, Allen J, Andrews R. Optimizing quality, service, and cost through innovation. Nursing administration quarterly. 2011; 35(1): 68-71. PMid: 21157266. http://dx.doi.org/10.1097/NAQ.0 b013e3182032208

[9] Wu I-L, Hsieh P-J. Understanding hospital innovation enabled customer-perceived quality of structure, process, and outcome care. Total Quality Management. 2011; 22(2): 227-41. http://dx.doi $. \circ \mathrm{rg} / 10.1080 / 14783363.2010 .532343$

[10] Heron DE, Godette KD, Wynn RA, et al. Radiation medicine innovations for the new millenium. Journal of the National Medical Association. 2003; 95(1): 55. PMid: 12656450.

[11] Winkler C, Duma M, Popp W, et al. Protection of quality and innovation in radiation oncology. Strahlentherapie und Onkologie. 2014 190(10): 950-6. PMid: 24658604. http://dx.doi.org/10.1007 /s00066-014-0615-3

[12] Martini A, Laugen BT, Gastaldi L, et al. Continuous innovation: Towards a Paradoxical, Ambidextrous combination of exploration and exploitation. International Journal of Technology Management 2013; 61(1): 1-22. http://dx.doi.org/10.1504/IJTM. 2013.0 50246

[13] O’Reilly III CA, Tushman ML. Ambidexterity as a dynamic capability: Resolving the innovator's dilemma. Research in organizational behavior. 2008; 28: 185-206. http://dx .doi .org/10.1016/j.r iob. 2008.06.002

[14] Damanpour F, Daniel Wischnevsky J. Research on innovation in organizations: Distinguishing innovation-generating from innovationadopting organizations. Journal of Engineering and Technology Management. 2006; 23(4): 269-91. http://dx.doi.org/10.1016/j .jengtecman. 2006.08.002

[15] van Poucke A. Towards radical innovation in knowledge-intensive service firms: Erasmus School of Economics (ESE). 2005.

[16] Adler PS, Goldoftas B, Levine DI. Flexibility versus efficiency? A case study of model changeovers in the Toyota production system. Organization science. 1999; 10(1): 43-68. http://dx.doi.org/1 0.1287 /orsc.10.1.43

[17] Cameron KS, Quinn RE. Diagnosing and changing organizational culture: Based on the competing values framework: John Wiley \& Sons; 2011.

[18] Savolainen TI. Cycles of continuous improvement: realizing competitive advantages through quality. International Journal of Operations \& Production Management. 1999; 19(11): 1203-22. http: //dx.doi.org/10.1108/01443579910291096

[19] McDermott CM, O'Connor GC. Managing radical innovation: an overview of emergent strategy issues. Journal of product innovation management. 2002; 19(6): 424-38. http://dx.doi.org/10.10 16/S0737-6782 (02) 00174-1

[20] Rosing K, Frese M, Bausch A. Explaining the heterogeneity of the leadership-innovation relationship: Ambidextrous leadership. The
Leadership Quarterly. 2011; 22(5): 956-74. http://dx.doi.org $/ 10.1016 / \mathrm{j}$. leaqua. 2011.07 .014

[21] Gamal D, Salah ET, Elrayyes EN. How to measure organization Innovativeness? Technology Innovation and Entrepreneurship Center. 2011.

[22] Hagedoorn J, Cloodt M. Measuring innovative performance: is there an advantage in using multiple indicators? Research policy. 2003; 32(8): 1365-79. http://dx.doi.org/10.1016/S0048-7 333(02) 00137-3

[23] Adams R, Bessant J, Phelps R. Innovation management measurement: A review. International Journal of Management Reviews. 2006; 8(1): 21-47. http://dx.doi.org/10.1111/j.1468-237 $0.2006 .00119 . \mathrm{x}$

[24] Van Leeuwen G. Linking innovation to productivity growth using two waves of the community Innovation Survey. OECD Publishing; 2002. http://dx.doi.org/10.1787/620221544571

[25] Djellal F, Gallouj F. Innovation in hospitals: a survey of the literature. The European Journal of Health Economics. 2007; 8(3): 181-93. PMid: 17186204. http://dx.doi.org/10.1007/s1019 8-006-0016-3

[26] Szczygielski K. What are service sector innovations and how do we measure them? CASE-Center for Social and Economic Research. 2011. PMid: 22000146.

[27] Smith K. Measuring innovation: Oxford University Press; 2005.

[28] Bloch C, Bugge MM. Public sector innovation-From theory to measurement. Structural Change and Economic Dynamics. 2013; 27: 13345. http://dx.doi.org/10.1016/j.strueco.2013.06.008

[29] Hipp C, Grupp H. Innovation in the service sector: The demand for service-specific innovation measurement concepts and typologies. Research policy. 2005; 34(4): 517-35. http://dx.doi.org/10. $1016 / j$.respol.2005.03.002

[30] Rose S, Shipp S, Lal B, et al. Frameworks for Measuring Innovation: Initial Approaches. Athena Alliance, Washington. 2009(s5).

[31] Milbergs E, Vonortas N. Innovation metrics: measurement to insight. Center for Accelerating Innovation and George Washington University, National Innovation Initiative 21st Century Working Group. 2004; 22.

[32] Kleinknecht A, Van Montfort K, Brouwer E. The non-trivial choice between innovation indicators. Economics of Innovation and new technology. 2002; 11(2): 109-21. http://dx.doi.org/10.1080 /10438590210899

[33] Makkonen T, van der Have RP. Benchmarking regional innovative performance: composite measures and direct innovation counts. Scientometrics. 2013; 94(1): 247-62. http://dx.doi.org/10.1007 /s11192-012-0753-2

[34] Dalkey NC, Brown BB, Cochran S. The Delphi method: An experimental study of group opinion: Rand Corporation Santa Monica, CA; 1969.

[35] Beretta R. A critical review of the Delphi technique. Nurse Researcher. 1996; 3: 79-89.

[36] Keeney S, Hasson F, McKenna H. Consulting the oracle: ten lessons from using the Delphi technique in nursing research. Journal of advanced nursing. 2006; 53(2): 205-12. PMid: 16422719. http://dx.doi.org/10.1111/j.1365-2648.2006.03716.x

[37] Keeney S, Hasson F, McKenna HP. A critical review of the Delphi technique as a research methodology for nursing. International journal of nursing studies. 2001; 38(2): 195-200. http://dx.doi.org /10.1016/S0020-7489(00)00044-4

[38] Hasson F, Keeney S, McKenna H. Research guidelines for the Delphi survey technique. Journal of advanced nursing. 2000; 32(4): 100815. http://dx.doi.org/10.1046/j.1365-2648.2000.t01-1 $-01567 . \mathrm{x}$ 
[39] Delbecq AL, Van de Ven AH, Gustafson DH. Group techniques for program planning: A guide to nominal group and Delphi processes: Scott, Foresman Glenview, IL; 1975. PMid: 126959.

[40] Linstone HA, Turoff M. Delphi: a brief look backward and forward. Technological Forecasting and Social Change. 2011; 78(9): 1712-9. http://dx.doi.org/10.1016/j.techfore.2010.09.011

[41] Valentini V, Aristei C, Glimelius B, et al. Multidisciplinary rectal cancer management: 2nd European rectal cancer consensus conference (EURECA-CC2). Radiotherapy and oncology. 2009; 92(2): 148-63. PMid: 19595467. http://dx.doi.org/10.1016/j.radonc . 20 09.06 .027

[42] Giuliani ME, Gillan C, Milne RA, et al. Determining an imaging literacy curriculum for radiation oncologists: an international Delphi study. International journal of radiation oncology, biology, physics. 2014; 88(4): 961-6. Epub 2014/03/13. PMid: 24606855. http://dx.doi.org/10.1016/j.ijrobp.2013.12.009

[43] Schumpeter JA. The theory of economic development: An inquiry into profits, capital, credit, interest, and the business cycle: Transaction Publishers; 1934.

[44] Brown BB. Delphi process: A methodology used for the elicitation of opinions of experts. DTIC Document. 1968.

[45] Kleinknecht A, Kleinknecht A, Bain D. Testing innovation indicators for postal surveys. New Concepts in Innovation Output Measurement Macmillan: London. 1993: 153-88.

[46] Van Zolingen SJ, Klaassen CA. Selection processes in a Delphi study about key qualifications in Senior Secondary Vocational Education. Technological forecasting and social change. 2003; 70(4): 317-40. http://dx.doi.org/10.1016/S0040-1625(02)00202-0

[47] Fagerberg J. Innovation: A guide to the literature. 2004.

[48] Walker RM, Jeanes E, Rowlands R. Measuring Innovation-Applying the Literature-Based Innovation Output Indicator to Public Services. Public Administration. 2002; 80(1): 201-14. http://dx.doi .org /10.1111/1467-9299.00300

[49] Fleuren M, Wiefferink K, Paulussen T. Determinants of innovation within health care organizations Literature review and Delphi study. International journal for quality in health care. 2004; 16(2): 107-23. PMid: 15051705. http://dx.doi.org/10.1093/intqhc/mzh0 30
[50] Oecd E. Oslo Manual. Proposed Guidelines for Collecting and Interpreting Innovation Data, $3^{\text {rd }}$ Edition Paris. 2005. http: //dx.doi .org/10.1787/9789264013100-en

[51] Brouwer E, Kleinknecht A. Innovative output, and a firm's propensity to patent: An exploration of CIS micro data. Research Policy. 1999; 28(6): 615-24. http://dx.doi.org/10.1016/S0048-7333 (99 ) 00003-7

[52] Coombs R, Narandren P, Richards A. A literature-based innovation output indicator. Research policy. 1996; 25(3): 403-13. http: //dx.doi.org/10.1016/0048-7333(95)00842-X

[53] Hollenstein H. A composite indicator of a firm's innovativeness. An empirical analysis based on survey data for Swiss manufacturing. Research Policy. 1996; 25(4): 633-45. http://dx.doi.org/10. 1016/0048-7333(95)00874-8

[54] Littell CL. Innovation in medical technology: reading the indicators. Health Affairs. 1994; 13(3): 226-35. PMid: 7927153. http: //dx.doi.org/10.1377/hlthaff.13.3.226

[55] Davila T, Epstein MJ, Shelton RD. The Creative Enterprise [Three Volumes]. Greenwood Publishing Group; 2006.

[56] Armbruster H, Bikfalvi A, Kinkel S, et al. Organizational innovation: The challenge of measuring non-technical innovation in large-scale surveys. Technovation. 2008; 28(10): 644-57. http: //dx.doi.org/10.1016/j.technovation.2008.03.003

[57] Sapprasert K, Clausen TH. Organizational innovation and its effects. Industrial and Corporate Change. 2012; 21(5): 1283-305. http://dx.doi.org/10.1093/icc/dts023

[58] Lam A. Organizational Innovation In: J. Fagerberg DCM, \& R. R. Nelson, editor. The Oxford handbook of Innovation. Oxford University Press: USA; 2004. 115-47.

[59] Rogers EM. Diffusion of innovations: Simon and Schuster; 2010.

[60] Willis GB, Smith T, Lee HJ. Do additional recontacts to increase response rate improve physician survey data quality? Medical care. 2013; 51(10): 945. PMid: 23969583. http://dx.doi.org/10.10 97/MLR . Ob013e3182a5023d

[61] Hikmet N, Chen SK. An investigation into low mail survey response rates of information technology users in health care organizations. International journal of medical informatics. 2003; 72(1): 29-34. PMid: 14644304. http://dx.doi.org/10.1016/j.ijmedinf . 2003.09.002 